\title{
Normal active range of motion of lower extremity joints of the healthy young adults in Cairo, Egypt
}

\author{
Shimaa T. Abu El Kasem ${ }^{1,2 *}$, Sobhy M. Aly ${ }^{3}$, Ehab M. Kamel ${ }^{4,5}$ and Hisham M. Hussein ${ }^{2,3}$
}

\begin{abstract}
Background: Range of motion (ROM) can be considered as one of the most commonly measured variables in musculoskeletal health care. When interpreting ROM, a common method is to compare obtained ROM values to normative data. So the current study aimed to establish (1) normative active ROM (AROM) values for lower extremity joints in young Egyptian adults, (2) compare the AROM between dominant and non-dominant lower extremity joints, and (3) compare between the values of AROM of lower extremity joints in both genders.

Results: Paired $t$-test demonstrated that there was statistical but not a clinical difference between the dominant and non-dominant ROM values of the lower extremity joints. Unpaired $t$-test revealed that there was statistical but not a clinical difference between male and female ROM values of lower extremity joints.

Conclusions: This study summarized normative data of Egyptian young adults; there were statistical but not a clinical difference between dominant and none dominant lower extremity joints in AROM and between males and females.
\end{abstract}

Keywords: Adult, Dominant and non-dominant side, Egypt, Normative AROM

\section{Background}

Range of motion (ROM) measurement is a basic assessment procedure in the medical field [1].The definition of ROM varies among published sources; Kapandji and colleagues described ROM as "the extent of osteokinematic motion available for movement activities, functional or otherwise, with or without assistance" [2].

The ROM has been routinely used to determine baseline limitations of motion, assess injuries in the musculoskeletal system, guide the choice of the appropriate therapeutic interventions, and document the effectiveness of these interventions [2-5].

Abnormalities in joint ROM can affect the level of performance; in the upper limbs, poor ROM can hinder the performance of simple daily activities $[1,6]$. While in the

\footnotetext{
*Correspondence: dr.shymaelshazly@yahoo.com

'Bein Essarayat, Giza, Egypt

2Department of Basic Science, Faculty of Physical Therapy, Cairo University, Cairo, Egypt

Full list of author information is available at the end of the article
}

lower limbs, ROM abnormalities may have an extensive impact on gait pattern [7], energy expenditure [8], and the distribution of forces within the spine and lower extremities [8].

The importance of ROM has encouraged health care professionals to search for more accurate data regarding the normal values of ROM to allow precise assessment and accurate comparison against these standard normal values [9].

The most popular sources for normative ROM references were usually extracted from different sources; the American Academy of Orthopedic Surgeons (AAOS), the American Medical Association (AMA) [10], and comparing to contralateral side, but there is till now contradiction and confusion in the available literature about using it as a source of normative ROM [11].

The data reported by these sources were extracted from old studies that encountered multiple methodological limitations. These limitations included undefined sample size, age, population characteristics, interracial, 
and between-gender variation in ROM. Moreover, the measurement tools or procedures, the type of motion measured either passive or active, were missed in these references [12].

Consequently, multiple attempts were conducted in order to establish normative reference values for ROM in younger subjects [13-15]. Other attempts were targeting adult [12] or older populations [16, 17].

It was reported from previous studies that ROM differs according to several factors like race and cultural habits [18]. Dominance is another factor that might affect normal ROM. This factor is not adequately studied. Literature shows controversy regarding the dominance effect on ROM ]10[. Few authors reported no differences between both sides $[5,10,11,19]$, while a significant difference was noticed in other studies $[12,20]$.

Gender can be considered as a factor that may affect normal ROM. Gender differences in ROM were reported on several occasions [21]. The variation in genetic and hormonal factors may describe these differences. Moreover, the difference in fat deposition between gender $[22,23]$ can also play a role.

According to the authors' best knowledge, no studies were conducted before to establish normative values for AROM in lower extremity joints on North African populations including Egyptians. Consequently, this study aimed to (1) establish normative AROM values for lower extremity joints in young Egyptian adults, (2) compare the AROM between dominant and non-dominant lower extremity joints, and (3) compare between the values of AROM of lower extremity joints in both genders.

\section{Methods}

\section{Study design and setting}

This cross-sectional study was performed at a local research laboratory during the period between January and October 2018 to measure the normal AROM of the hip, knee, and ankle joints in healthy young adults. The study was ethically approved by local ethical committee board with number NO: P.T.REC/012/001698.

\section{Subjects}

There are a total of 1000 subjects (500 males and 500 females); their age ranged from 18 to 30 years, and body mass index (BMI) range from 18 to $24.9 \mathrm{~kg} / \mathrm{m}^{2}$. Subjects were participated in the study after assigned a written consent form and recruited through written advertisements, verbal announcements, and social media.

Subjects were excluded if they were participating in regular sports involving lower extremity, heavy-duty workers, obese or underweight, undergoing physical therapy procedures for lower extremity joints during the last 6 months, and had any previous fractures, injury, or surgery involving the lower extremity. Subjects with joint pain, musculoskeletal disorders, neurological dysfunction, and pregnant women were also excluded from the study (Fig. 1).

\section{Procedure}

One 9-year experienced therapist performed all measurements. A universal transparent goniometer was used to obtain the AROM of all lower extremity joints. The universal goniometer has acceptable reliability, and it is commonly used in clinical practice to assess AROM [3, 10, 24].

Because measuring technique and patient positioning may affect ROM [25, 26], the standardized guidelines and instructions prescribed by Norkin and White were followed during measurements (Table 2) [27].

A pilot study was conducted on 20 participants at two successive days before the main experiment to examine the intra-rater reliability of the measurements. Intra-rater reliability of ROM measurement showed excellent reliability in both dominant and non-dominant sides. Intraclass correlation coefficient (ICC) ranged from 0.91 to 0.99 (Table 1). Measurements and procedures were replicated from the study conducted by Macedo and colleagues [11].

The recruited subjects signed a consent form after they were screened for eligibility to join the study. Demographic data were collected [28], and limb dominance was determined according to the limb selfpreferred by the subjects to kick a football [29]. This limb-dominance determination technique is reliable and has a $97.7 \%$ agreement with task performance [30]. Subjects were instructed to wear light nonrestrictive clothes, and a universal plastic goniometer with $30 \mathrm{~cm}$ arms and $360^{\circ}$ protractor (Baseline ${ }^{\circ}$ HPMS Inc, USA) was used to perform all the measurements (Table 2). In order to avoid the carryover effect, measurements were carried out in random order; each movement was performed 3 times, and the average was taken.

\section{Statistical analysis}

Descriptive statistics in the form of mean and standard deviation were used to present the measured parameters. Normal distribution of data was checked using the Shapiro-Wilk test. Paired $t$-tests were used to compare between the dominant and non-dominant lower extremity ROM values. Unpaired $t$-test was used to compare lower extremity ROM values between males and females. The level of significance was set at $p \leq 0.05$. All statistical tests were performed through the statistical package for social studies (SPSS) version 25 for windows (IBM SPSS, Chicago, IL, USA).

\section{Results}

\section{Subject characteristics}

This study recruited 1000 Egyptian young adults with an equal number of males and females with a mean age of 


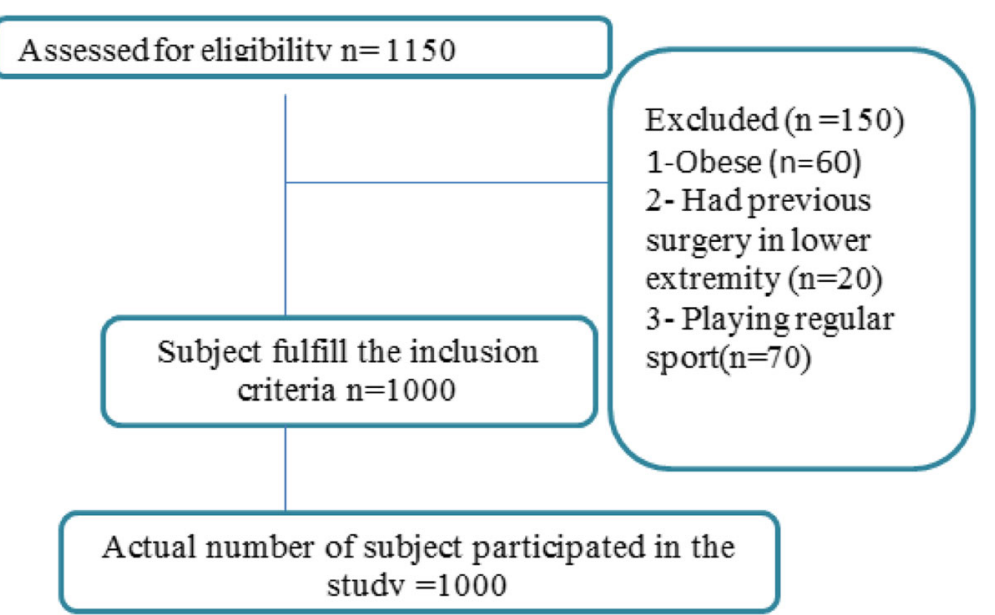

Fig. 1 Flow chart for participants in the study

20.98 years. Eight hundred eighty-eight subjects had the right side dominant while 112 subjects had the left side dominant. Subjects' demographic data was summarized in Table 3.

\section{Lower limbs AROM}

Lower limb AROM data of dominant and non-dominant sides are presented in Table 4 . Results revealed statistically significant differences between dominant and nondominant sides in hip flexion and extension, hip adduction, hip external and internal rotation, knee flexion, and ankle eversion $(p \leq 0.05)$. The mean difference in all measurements is very low.

The comparison between males and females showed significant differences in all movements except hip extension and adduction of both dominant and non-dominant sides in addition to the internal rotation of the nondominant side $(p<0.05)$ (Table 5$)$. The mean difference

Table 1 Intra-rater reliability for ROM measurement

\begin{tabular}{lll}
\hline & ICC (95\% Cl) & \\
\cline { 2 - 3 } & Dominant & Non-dominant \\
\hline Hip flexion & $0.99(0.99: 0.99)$ & $0.99(0.97: 0.99)$ \\
Hip extension & $0.98(0.97: 0.99)$ & $0.96(0.91: 0.98)$ \\
Hip abduction & $0.99(0.99: 0.99)$ & $0.98(0.97: 0.99)$ \\
Hip adduction & $0.97(0.94: 0.98)$ & $0.96(0.91: 0.98)$ \\
Hip external rotation & $0.94(0.87: 0.97)$ & $0.95(0.85: 0.97)$ \\
Hip internal rotation & $0.95(0.91: 0.98)$ & $0.96(0.91: 0.98)$ \\
Knee flexion/extension & $0.99(0.99: 0.99)$ & $0.99(0.97: 0.99)$ \\
Ankle dorsiflexion & $0.97(0.93: 0.98)$ & $0.98(0.97: 0.99)$ \\
Ankle plantar flexion & $0.94(0.88: 0.97)$ & $0.94(0.87: 0.97)$ \\
Foot eversion & $0.91(0.8: 0.95)$ & $0.92(0.83: 0.96)$ \\
Foot inversion & $0.93(0.86: 0.97)$ & $0.93(0.84: 0.97)$ \\
\hline
\end{tabular}

ICC intraclass correlation coefficient, $\mathrm{Cl}$ confidence interval in all occasions was trivial and did not reach the clinical significance difference described previously [31].

\section{Discussion}

Up to the authors' best knowledge, this study is the first attempt to establish normative AROM data for the lower extremity joints in young Egyptian adults. This study is also among the few studies that were performed in the Middle East [18, 32].

Owing to the limitations encountered in data obtained by the AMA and AAOS and the hypothesized influences of gender and limb dominance on normative values of ROM, there is an increased need for nationally based standard references (normative) databases for joint ROM.

The major findings of the current study were as follows:

- Normative AROM data for lower extremity joints in young Egyptian adults were summarized.

- There were no clinically significant differences between dominant and non-dominant sides in AROM for all lower extremity joints.

- There were no clinically significant differences in ROM between males and females.

Various studies were conducted before to establish normative ROM values in many countries such as Iran [33], India [34], Sweden [5], Saudi Arabia [18], Nigeria [35], Iraq [36], and Turkey [10]. Only two studies addressed the Middle Eastern population. However, both are old, and they were conducted on a small population.

Although statistically significant differences in AROM which were demonstrated between dominant and nondominant sides, they could be neglected clinically [31] Therefore, the current study supports the use of the ROM of the health joint as a reference for the diseased one. This 
Table 2 Subject positioning and goniometer placement during active range of motion measurement

\begin{tabular}{|c|c|c|c|c|}
\hline $\begin{array}{l}\text { Joint } \\
\text { movement }\end{array}$ & $\begin{array}{l}\text { Subject } \\
\text { position }\end{array}$ & Fixed arm of goniometer & Movable arm of goniometer & Fulcrum \\
\hline $\begin{array}{l}\text { Hip } \\
\text { - Flexion } \\
\text { - Extension }\end{array}$ & $\begin{array}{l}\text { Supine } \\
\text { prone }\end{array}$ & Lateral midline of the pelvis & $\begin{array}{l}\text { Lateral midline of the femur toward the } \\
\text { lateral femoral epicondyle }\end{array}$ & Over the greater trochanter \\
\hline $\begin{array}{l}\text { - Abduction } \\
\text { - Adduction }\end{array}$ & Supine & $\begin{array}{l}\text { Placed on a line between the } \\
\text { anterior superior iliac spines }\end{array}$ & $\begin{array}{l}\text { Parallel to the anterior midline of the femur } \\
\text { toward the midline of the patella }\end{array}$ & The ASIS of the tested side \\
\hline - Hip & $\begin{array}{l}\text { Sitting on } \\
\text { table edge }\end{array}$ & Parallel to the ground & Parallel to the tibia & Anterior aspect of the patella \\
\hline $\begin{array}{l}\text { Knee* } \\
\text { - Flexion/ } \\
\text { extension }\end{array}$ & Supine & $\begin{array}{l}\text { Parallel to the lateral midline of } \\
\text { the femur }\end{array}$ & Parallel to the lateral midline of the fibula & The lateral epicondyle of the femur \\
\hline $\begin{array}{l}\text { Ankle } \\
\text { - } \\
\text { Dorsiflexion } \\
\text { - Planter } \\
\text { flexion }\end{array}$ & $\begin{array}{l}\text { Sitting on } \\
\text { table edge }\end{array}$ & $\begin{array}{l}\text { Placed parallel to the lateral } \\
\text { midline of the fibula }\end{array}$ & $\begin{array}{l}\text { Placed parallel to the lateral midline of the } \\
\text { fifth metatarsal bone }\end{array}$ & $\begin{array}{l}\text { Over the lateral aspect of the lateral } \\
\text { malleolus }\end{array}$ \\
\hline $\begin{array}{l}\text { Subtalar } \\
\text { - Eversion } \\
\text { - Inversion }\end{array}$ & Prone & $\begin{array}{l}\text { Over the posterior midline of the } \\
\text { lower leg }\end{array}$ & Over the posterior midline of the calcaneus & $\begin{array}{l}\text { Over the posterior aspect of the ankle } \\
\text { midway between the malleoli }\end{array}$ \\
\hline
\end{tabular}

ASIS anterior superior iliac spine

*Knee joint extension is considered 0 (full extension) position, and flexion was measured from it

conclusion was also reported previously [10, 11, 37]. On the other hand, Gunal and colleagues in 1996 reported significant differences between both sides, and consequently, they doubted the reliability of using the contralateral side as a reference [38]; the cause of the difference between Gunal findings and ours may be argued to the differences in tested extremity, while the lower extremity was tested in the current study, Gunal and colleagues tested upper extremity; it is well known that the difference between dominant and non-dominant sides is obvious in upper extremity than lower extremity. Moreover, all participants included in Gunal study were right handed.

The lack of dominance related clinically significant differences could be attributed to the similarity of effort exerted by both lower limbs during ambulation, which is the main activity performed by the lower limbs in healthy nonathletic subjects.

The current study reported that gender has no clinical influence on AROM of lower extremity joints so that we agree with the findings which were reported in a previous work $[10,21]$.

Two previous studies reported no significant differences between both genders. However, their conclusion relied

Table 3 Subjects' demographic

\begin{tabular}{lllll}
\hline & \multicolumn{4}{l}{ Subjects demographic data } \\
\cline { 2 - 5 } & Age (years) & Weight $(\mathrm{kg})$ & Height $\left(\mathrm{cm}^{2}\right)$ & BMI $\left(\mathrm{kg} / \mathrm{m}^{2}\right)$ \\
\hline Mean & 20.98 & 71.45 & 173.9 & 23.62 \\
SD & 1.83 & 4.32 & 4.21 & 1.21 \\
\hline
\end{tabular}

on statistical significant differences but not clinically meaningful values $[10,21]$. At the same time, statistically significant differences were reported between both genders in other experiments [39-41,25].

The small clinically insignificant gender differences in ROM may be attributed to the narrow age range of the current study sample that limits the effect of age-related changes in body composition [42, 43]. The normal BMI that characterizes the recruited sample may also influence these results.

\section{Clinical implication}

This study provides reference data for AROM of lower extremity joints in Egyptian young adults. This data can be used during the rehabilitation process. This study supports the use of the contralateral healthy limb as a reference for the normal values of the affected limb and supports the similarity of the AROM values in males and females.

\section{Limitation}

The results of this study should be used with cautions because of the following limitations: the authors did not determine the appropriate sample size, but it was estimated depending on the samples used in the previous study a priori; the study includes to specific age group, and the findings might be not applicable to other age groups; the time of the assessment was not consistent through the study but to control this variable; and measurements were avoided in the early morning. Moreover, all patients were allowed to rest for $15 \mathrm{~min}$ before taking measurements. 
Table 4 Mean values of lower limb ROM of dominant and non-dominant sides

\begin{tabular}{lllll}
\hline & Dominant & Non-dominant & MD (95\% Cl) & $p$ value \\
\hline Hip flexion & $125.93 \pm 6.44$ & $125.62 \pm 6.5$ & $0.31(0.11: 0.52)$ & $0.003^{* *}$ \\
Hip extension & $19.51 \pm 4.08$ & $19.31 \pm 3.95$ & $0.2(0.07: 0.33)$ & $0.003^{* *}$ \\
Hip abduction & $42.23 \pm 5.66$ & $42.07 \pm 5.57$ & $0.16(-0.03: 0.34)$ & 0.093 \\
Hip adduction & $28.21 \pm 4.78$ & $28.02 \pm 4.76$ & $0.2(0.03: 0.36)$ & $0.018^{* *}$ \\
Hip external rotation & $37.61 \pm 4.23$ & $37.47 \pm 4.34$ & $0.14(0.07: 0.2)$ & $0.001^{* *}$ \\
Hip internal rotation & $27.91 \pm 2.5$ & $28.35 \pm 2.7$ & $-0.44(-0.55:-0.33)$ & $0.001^{* *}$ \\
Knee flexion/extension & $137.53 \pm 4.6$ & $137.24 \pm 4.72$ & $0.28(0.1: 0.47)$ & $0.002^{* *}$ \\
Ankle dorsiflexion & $20.72 \pm 4.08$ & $20.67 \pm 3.95$ & $-0.06(-0.06: 0.17)$ & 0.353 \\
Ankle plantar flexion & $49.8 \pm 6.51$ & $49.85 \pm 6.44$ & $0.14(0.07: 0.2)$ & $0.07)$ \\
Foot eversion & $15.52 \pm 1.5$ & $15.38 \pm 1.54$ & $-0.04(-0.10: 0.02)$ & 0.001 \\
Foot inversion & $35.22 \pm 2.14$ & $35.26 \pm 2.09$ & 0.225 \\
\hline
\end{tabular}

Data are expressed as mean \pm SD

$M D$ mean difference

${ }^{* *} p$ value $\leq 0.05$ significant

Table 5 Comparison of mean values of lower limb ROM between males and females

\begin{tabular}{|c|c|c|c|c|c|}
\hline & & Males & Females & MD $(95 \% \mathrm{Cl})$ & $p$ value \\
\hline \multirow[t]{2}{*}{ Hip flexion } & Dominant & $123.14 \pm 4.55$ & $128.73 \pm 6.84$ & $-5.6(-6.31:-4.87)$ & $0.001^{* *}$ \\
\hline & Non-dominant & $122.82 \pm 4.84$ & $128.42 \pm 6.72$ & $-5.6(-6.31:-4.87)$ & $0.001^{* *}$ \\
\hline \multirow[t]{2}{*}{ Hip extension } & Dominant & $19.39 \pm 3.65$ & $19.62 \pm 4.47$ & $-0.23(-0.73: 0.27)$ & 0.377 \\
\hline & Non-dominant & $19.13 \pm 3.56$ & $19.48 \pm 4.30$ & $-0.35(-0.83: 0.14)$ & 0.164 \\
\hline \multirow[t]{2}{*}{ Hip abduction } & Dominant & $39 \pm 2.98$ & $45.47 \pm 5.86$ & $-6.47(-7.04:-5.89)$ & $0.001^{* *}$ \\
\hline & Non-dominant & $38.83 \pm 3.15$ & $45.31 \pm 5.58$ & $-6.48(-7.04:-5.92)$ & $0.001^{* *}$ \\
\hline \multirow[t]{2}{*}{ Hip adduction } & Dominant & $28.19 \pm 4.1$ & $28.23 \pm 5.38$ & $-0.04(-0.62: 0.55)$ & 0.905 \\
\hline & Non-dominant & $28.07 \pm 4.26$ & $27.96 \pm 5.21$ & $0.11(-0.48: 0.7)$ & 0.715 \\
\hline \multirow[t]{2}{*}{ Hip external rotation } & Dominant & $36 \pm 4.61$ & $39.22 \pm 3.06$ & $-3.22(-3.7:-2.73)$ & $0.001^{* *}$ \\
\hline & Non-dominant & $35.72 \pm 4.69$ & $39.23 \pm 3.08$ & $-3.51(-4:-3.01)$ & $0.001^{* *}$ \\
\hline \multirow[t]{2}{*}{ Hip internal rotation } & Dominant & $27.68 \pm 2.64$ & $28.15 \pm 2.33$ & $-0.47(-0.78:-0.16)$ & $0.003^{* *}$ \\
\hline & Non-dominant & $28.5 \pm 3.09$ & $28.2 \pm 2.21$ & $0.31(-0.02: 0.63)$ & 0.072 \\
\hline \multirow[t]{2}{*}{ Knee flexion/extension } & Dominant & $137.22 \pm 4.13$ & $137.84 \pm 5.01$ & $-0.63(-1.19:-0.05)$ & $0.031^{* *}$ \\
\hline & Non-dominant & $136.89 \pm 3.97$ & $137.6 \pm 5.35$ & $-0.71(-1.29:-0.12)$ & $0.018^{* *}$ \\
\hline \multirow[t]{2}{*}{ Ankle dorsi flexion } & Dominant & $21 \pm 3.24$ & $20.46 \pm 4.76$ & $0.54(0.03: 1.04)$ & $0.038^{* *}$ \\
\hline & Non-dominant & $21.04 \pm 3.18$ & $20.29 \pm 4.57$ & $0.75(0.26: 1.24)$ & $0.003^{* *}$ \\
\hline \multirow[t]{2}{*}{ Ankle planter flexion } & Dominant & $49 \pm 5.88$ & $50.58 \pm 7$ & $-1.59(-2.38:-0.78)$ & $0.001^{* *}$ \\
\hline & Non-dominant & $49.14 \pm 6.01$ & $50.55 \pm 6.78$ & $-1.41(-2.2:-0.61)$ & $0.001^{* *}$ \\
\hline \multirow[t]{2}{*}{ Eversion } & Dominant & $15.08 \pm 1.6$ & $15.95 \pm 1.25$ & $-0.87(-1.05:-0.69)$ & $0.001^{* *}$ \\
\hline & Non-dominant & $15.07 \pm 1.56$ & $15.7 \pm 1.45$ & $-0.63(-0.81:-0.44)$ & $0.001^{* *}$ \\
\hline \multirow[t]{2}{*}{ Inversion } & Dominant & $34.2 \pm 2.14$ & $36.25 \pm 1.56$ & $-2.06(-2.29:-1.82)$ & $0.001^{* *}$ \\
\hline & Non-dominant & $34.3 \pm 2.15$ & $36.22 \pm 1.5$ & $-1.93(-2.15:-1.69)$ & $0.001^{* *}$ \\
\hline
\end{tabular}

Data are expressed as mean \pm SD 


\section{Conclusion}

This study identified normative ROM data for Egyptian young adults. The current study concluded that there were statistical but not a clinical difference between dominant and non-dominant sides and between males and females in AROM of the lower limb joints among Egyptian young adults.

\section{Abbreviations}

AROM: Active range of motion; AAOS: American Academy of Orthopedic Surgeons; AMA: American Medical Association; BMl: Body mass index SPSS: Statistical package for social studies; ROM: Range of motion

\section{Acknowledgements}

The authors thank all participants in the study for their cooperation.

\section{Authors' contributions}

H.M.H formulated the idea, collected the data, critically reviewed, and approved the final draft. S.M.A and S.T.E were responsible for clinical evaluation and carried out the statistical analysis. E.M.K collected the literature and assisted in writing the original draft. All authors were responsible for the content and similarity index of the manuscript. The authors read and approved the final manuscript.

\section{Availability of data and materials}

Not applicable

\section{Ethics approval and consent to participate}

The study was ethically approved by the local ethical committee board with number NO: P.T.REC/012/001698. Subjects were participated in the study after assigned a written consent.

\section{Consent for publication}

Not applicable

\section{Competing interests}

Authors declare that there are no competing interests.

\section{Author details}

${ }^{1}$ Bein Essarayat, Giza, Egypt. ²Department of Basic Science, Faculty of Physical Therapy, Cairo University, Cairo, Egypt. ${ }^{3}$ Department of Biomechanics, Faculty of Physical Therapy, Cairo University, Cairo, Egypt. ${ }^{4}$ Department of Physical Therapy, College of Applied Medical Sciences, University of Hail, Hail, Saudi Arabia. ${ }^{5}$ Department of Physical Therapy, El Helal Hospital, Cairo, Egypt.

Received: 6 May 2020 Accepted: 3 June 2020

Published online: 05 August 2020

\section{References}

1. Clapper MP, Wolf SL. Comparison of the reliability of the Orthoranger and the standard goniometer for assessing active lower extremity range of motion. Phys Ther. 1988;68(2):214-8.

2. Kapandji Al. The clinical evaluation of the upper limb joints' function: back to Hippocrates. Hand Clin. 2003;19(3):379-86.

3. Gajdosik RL, Bohannon RW. Clinical measurement of range of motion Review of goniometry emphasizing reliability and validity. Phys Ther. 1987 67(12):1867-72.

4. Awan R, Smith J, Boon AJ. Measuring shoulder internal rotation range of motion: a comparison of 3 techniques. Arch Phys Med Rehabil. 2002:83(9): 1229-34.

5. Roaas A, Andersson GB. Normal range of motion of the hip, knee and ankle joints in male subjects, 30-40 years of age. Acta Orthop Scand. 1982;53(2): 205-8.

6. Braddom RL. Physical medicine and rehabilitation: Elsevier Health Sciences; 2010.

7. Riley PO, Della Croce U, Kerrigan DC. Effect of age on lower extremity join moment contributions to gait speed. Gait Posture. 2001;14(3):264-70.
8. McGregor A, Hukins D. Lower limb involvement in spinal function and low back pain. Journal of back and musculoskeletal rehabilitation. 2009;22(4): 219-22.

9. Rau G, Disselhorst-Klug C, Schmidt R. Movement biomechanics goes upwards: from the leg to the arm. J Biomech. 2000;33(10):1207-16.

10. Hallaceli H, Uruc V, Uysal HH, Ozden R, Hallaceli C, Soyuer F, et al. Normal hip, knee and ankle range of motion in the Turkish population. Acta Orthop Traumatol Turc. 2014;48(1):37-42.

11. Macedo LG, Magee DJ. Differences in range of motion between dominant and nondominant sides of upper and lower extremities. J Manip Physiol Ther. 2008;31(8):577-82.

12. GÜNAL I, KÖSE N, Erdogan O, GÖKTÜRK E, Seber S. Normal range of motion of the joints of the upper extremity in male subjects, with special reference to side. J Bone Joint Surg Am. 1996;78(9):1401-4.

13. De Carlo MS, Sell KE. Normative data for range of motion and single-leg hop in high school athletes. J Sport Rehabil. 1997;6(3):246-55.

14. Drews JE, Vraciu JK, Pellino G. Range of motion of the joints of the lower extremities of newborns. Physical \& Occupational Therapy In Pediatrics. 1984;4(2):49-63.

15. Svenningsen S, Terjesen T, Auflem M, Berg V. Hip motion related to age and sex. Acta Orthop Scand. 1989:60(1):97-100.

16. Desrosiers J, Hébert R, Bravo G, Dutil É. Shoulder range of motion of healthy elderly people: a normative study. Physical \& Occupational Therapy In Geriatrics. 1995;13(1-2):101-14.

17. Fiebert IM, Downey PA, Brown JS. Active shoulder range of motion in persons aged 60 years and older. Physical \& Occupational Therapy in Geriatrics. 1995;13(1-2):115-28.

18. Ahlberg A, Moussa M, Al-Nahdi M. On geographical variations in the normal range of joint motion. Clin Orthop Relat Res. 1988;234:229-31.

19. Barnes CJ, Van Steyn SJ, Fischer RA. The effects of age, sex, and shoulder dominance on range of motion of the shoulder. J Shoulder Elb Surg. 2001; 10(3):242-6.

20. Allander E, Björnsson O, Olafsson O, Sigfusson N, Thorsteinsson J. Normal range of joint movements in shoulder, hip, wrist and thumb with special reference to side: a comparison between two populations. Int J Epidemiol. 1974:3(3):253-61.

21. Doriot $N$, Wang $X$. Effects of age and gender on maximum voluntary range of motion of the upper body joints. Ergonomics. 2006;49(3):269-81.

22. Geer $E B$, Shen W. Gender differences in insulin resistance, body composition, and energy balance. Gender medicine. 2009;6:60-75.

23. Shaw NJ, Crabtree NJ, Kibirige MS, Fordham JN. Ethnic and gender differences in body fat in British schoolchildren as measured by DXA. Arch Dis Child. 2007:92(10):872-5.

24. Kilber M, Hanney W. The reliability and concurrent validity of shoulder mobility measurements using a digital inclinometer and goniometer. A technical report Ant J Sports Phys Ther. 2012;2012.

25. Cho $\mathrm{KH}$, Jeon $\mathrm{Y}$, Lee $\mathrm{H}$. Range of motion of the ankle according to pushing force, gender and knee position. Ann Rehabil Med. 2016;40(2):271-8.

26. Santos CM, Ferreira G, Malacco PL, Sabino GS, Moraes GFS, Felício DC. Intra and inter examiner reliability and measurement error of goniometer and digital inclinometer use. Rev Bras Med Esporte. 2012;18(1):38-41.

27. Norkin CC, White DJ. Measurement of joint motion: a guide to goniometry: FA Davis; 2016.

28. Walker JM, Sue D, Miles-Elkousy N, Ford G, Trevelyan H. Active mobility of the extremities in older subjects. Phys Ther. 1984;64(6):919-23.

29. Brown AM, Zifchock RA, Hillstrom HJ. The effects of limb dominance and fatigue on running biomechanics. Gait Posture. 2014;39(3):915-9.

30. Coren S, Porac C. The validity and reliability of self-report items for the measurement of lateral preference. Br J Psychol. 1978;69(2):207-11.

31. Cocchiarella L, Andersson G. Guides to the evaluation of permanent impairment: Amer Medical Assn; 2001.

32. Al-Rawi ZS. al-aszawi AJ, AL-CHALABI T. Joint mobility among university students in Iraq. Rheumatology. 1985;24(4):326-31.

33. Khalvat A, Razavizadeh M. A prospective cross-sectional study of joint motion in healthy adult subjects. Acta Medica Iranica. 2005;43(2):151-4.

34. Kumar S, Sharma R, Gulati D, Dhammi IK, Aggarwal AN. Normal range of motion of hip and ankle in Indian population. Acta Orthop Traumatol Turc. 2010:45(6):421-4.

35. Egwu M, Mbada C, Olowosejeje D. Normative values of spinal flexibility for Nigerians using the inclinometric technique. Journal of Exercise Science and Physiotherapy. 2012;8(2):93. 
36. Al-Rawi ZS, Al-Aszawi AJ, Al-Chalabi T. Joint mobility among university students in Iraq. Br J Rheumatol. 1985;24(4):326-31.

37. Stefanyshyn DJ, Engsberg JR. Right to left differences in the ankle joint complex range of motion. J Biomech. 1994;27(6):816.

38. Gunal I, Kose N, Erdogan O, Gokturk E, Seber S. Normal range of motion of the joints of the upper extremity in male subjects, with special reference to side. JBJS. 1996;78(9):1401-4.

39. Soucie J, Wang C, Forsyth A, Funk S, Denny M, Roach K, et al. Range of motion measurements: reference values and a database for comparison studies. Haemophilia : the official journal of the World Federation of Hemophilia. 2011:17(3):500-7.

40. Simoneau GG, Hoenig KJ, Lepley JE, Papanek PE. Influence of hip position and gender on active hip internal and external rotation. J Orthop Sports Phys Ther. 1998;28(3):158-64.

41. Chateauroux E, Wang X, Pudlo P. Age and gender effects on joint ranges of motion of the main joints involved in car accessibility movements. Computer Methods in Biomechanics and Biomedical Engineering. 2007: 10(sup 1):177-178.

42. Heitmann B. Body fat in the adult Danish population aged 35-65 years: an epidemiological study. Int J Obes. 1991;15(8):535-45.

43. Nagy TR, Gower BA, Trowbridge CA, Dezenberg C, Shewchuk RM, Goran MI. Effects of gender, ethnicity, body composition, and fat distribution on serum leptin concentrations in children. The Journal of Clinical Endocrinology \& Metabolism. 1997;82(7):2148-52.

\section{Publisher's Note}

Springer Nature remains neutral with regard to jurisdictional claims in published maps and institutional affiliations.

\section{Submit your manuscript to a SpringerOpen ${ }^{\circ}$ journal and benefit from:}

- Convenient online submission

- Rigorous peer review

- Open access: articles freely available online

- High visibility within the field

- Retaining the copyright to your article

Submit your next manuscript at $\boldsymbol{\nabla}$ springeropen.com 